\title{
Dynamic microangiography of the gastrointestinal mucosa using magnifying Blue Light Imaging
}

With the emergence of image-enhanced endoscopy (IEE), it is no longer difficult to visualize the microvasculature in the gastrointestinal (GI) tract [1,2]. Magnifying Blue Light Imaging (BLI; Fujifilm, Tokyo, Japan) provides enhanced images of superficial vessels in the GI tract as hemoglobin absorbs light with a narrow wavelength. A substantial number of studies using Blue Light Imaging have been conducted, but none of them have focused on its advantage in visualizing the dynamic microvascular architecture with the microcirculation of red blood cells. We attempted to visualize the microcirculation in the Gl tract using magnifying Blue Light Imaging ( $\triangleright$ Video 1, $>$ Fig. 1). We used the distal attachment or soft hood to stabilize the distance between the tip of the scope and mucosal surface, as previously reported by Yao et al. [3]. We used the zoom function, which provided up to approximately 135 times magnification. In addition to using the cap, we observed the mucosa underwater to obtain clearer images. In the esophagus, intrapapillary capillary loops were observed at the end of long branching mucosal vessels [4]. In the duodenum and ileum, a loop-like formation of the capillary network was observed within the villi. In the colon, a honeycomb-like subepithelial capillary network was observed [3]. In the rectum, distinctly different from the colon, long branching vessels were heterogeneously distributed with various densities. Using magnifying Blue Light Imaging, it was possible to visualize the microcirculation owing to the rapid movement of red blood cells in the capillaries. The use of a cap and water was significant.

Utilizing the technique described here, analysis of the microcirculation is possible, thereby suggesting a new approach that could be used to investigate the pathology of diseases such as inflammatory bowel disease, functional Gl disorders, and celiac disease.

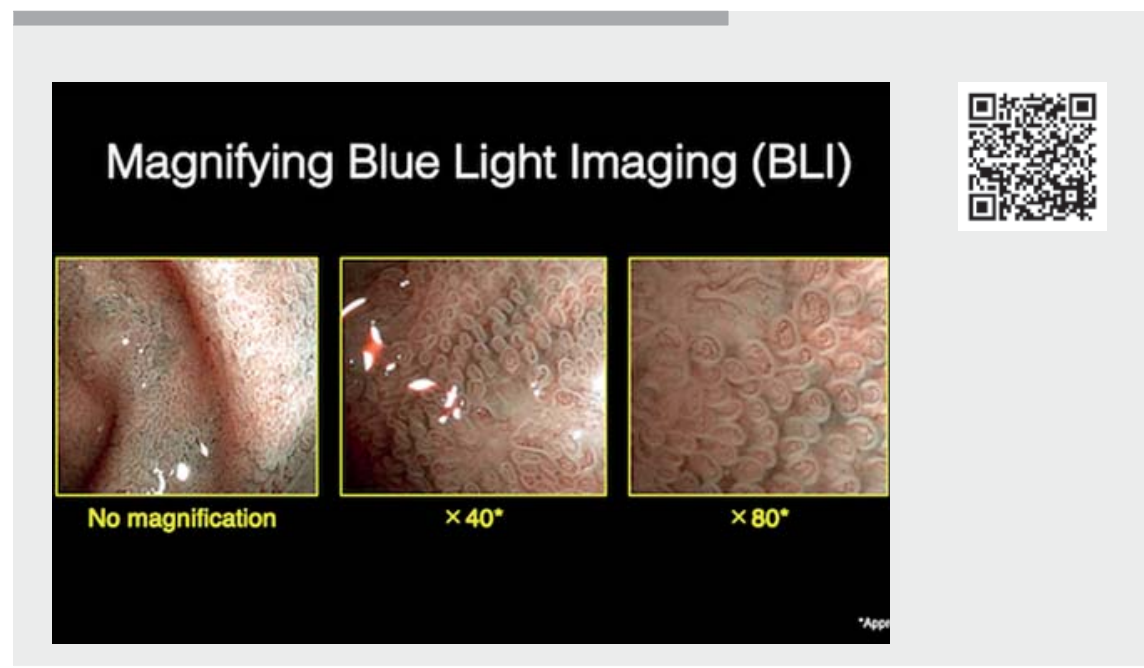

$\checkmark$ Video 1 Endoscopic dynamic visualization of the microcirculation in the gastrointestinal mucosa using magnifying Blue Light Imaging.

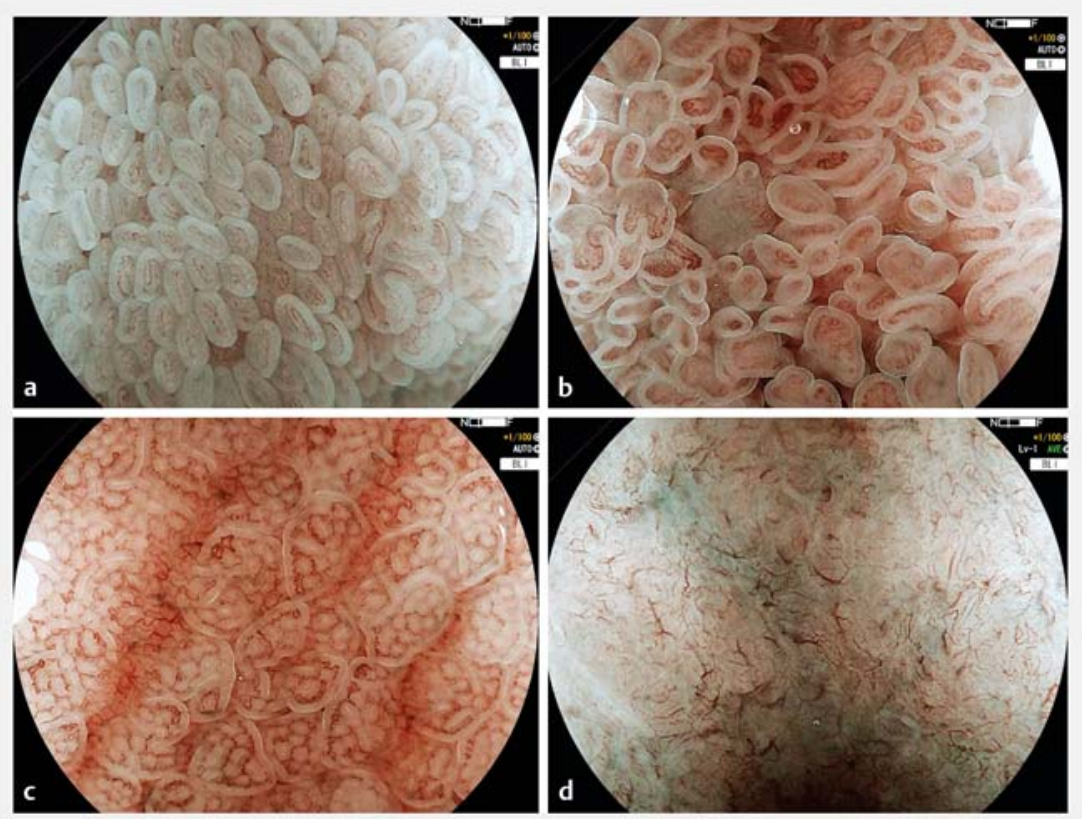

- Fig. 1 Microcirculation was visualized as dynamic movement of blood cells in the capillary network within the gastrointestinal mucosa. a lleum. b Duodenum. c Stomach. d Rectum.

Endoscopy_UCTN_Code_CCL_1AB_2AC_3AH 


\section{Competing interests}

Shunsuke Yamamoto disclose no financial relationships or conflicts of interests relevant to this publication. Helmut Neumann is a consultant for Fujifilm.

The authors

Shunsuke Yamamoto ${ }^{1}$, Helmut Neumann²

1 Department of Gastroenterology and Hepatology, National Hospital Organization Osaka National Hospital, Osaka, Japan

2 Department of Medicine I, University Medical Center Mainz, Mainz, Germany

Corresponding author

\section{Shunsuke Yamamoto, MD}

Department of Gastroenterology and Hepatology, National Hospital Organization Osaka National Hospital, 2-1-14 Houenzaka, Chuo-ku, Osaka, 540-0006, Japan

shun0515suke@gmail.com

\section{References}

[1] Yao K, Oishi T, Matsui T et al. Novel magnified endoscopic findings of microvascular architecture in intramucosal gastric cancer. Gastrointest Endosc 2002; 56: 279-284

[2] Sano Y, Horimatsu T, Fu KI et al. Magnifying observation of microvascular architecture of colorectal lesions using a narrow-band imaging system. Dig Endsc 2006; 18: S44S51

[3] Yao K, Anagnostopoulos GK, Jawhari AU et al. Optical microangiography: high-definition magnification colonoscopy with Narrow Band Imaging (NBI) for visualizing mucosal capillaries and red blood cells in the large intestine. Gut Liver 2008; 2: 14-18

[4] Inoue H, Kumagai Y, Yoshida T et al. Highmagnification endoscopic diagnosis of the superficial esophageal cancer. Dig Endsc 2000; 12: S32-\$35

\section{Bibliography}

Endoscopy 2022; 54: E121-E122

DOI 10.1055/a-1418-7303

ISSN 0013-726X

published online 16.4.2021

(c) 2021. Thieme. All rights reserved.

Georg Thieme Verlag KG, Rüdigerstraße 14,

70469 Stuttgart, Germany

\section{ENDOSCOPY E-VIDEOS}

https://eref.thieme.de/e-videos

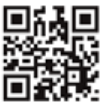

Endoscopy E-Videos is an open access online section, reporting on interesting cases and new techniques in gastroenterological endoscopy. All papers include a high quality video and all contributions are freely accessible online. Processing charges apply (currently EUR 375), discounts and wavers acc. to HINARI are available.

This section has its own submission website at

https://mc.manuscriptcentral.com/e-videos 